FULL SCALE TESTING OF AN ASPIRATING FACE SEAL WITH ANGULAR MISALIGNMENT

\author{
Norm Turnquist \\ General Electric Corporate Research and Development \\ Niskayuna, New York \\ Alan D. McNickle \\ Stein Seal, Co. \\ Kulpsville, Pennsylvania \\ Thomas W. Tseng \\ General Electric Aircraft Engines \\ Cincinnati, Ohio \\ Bruce M. Steinetz \\ National Aeronautics and Space Administration \\ Glenn Research Center \\ Cleveland, Ohio
}

\title{
Full Scale Testing of an Aspirating Face Seal with Angular Misalignment
}

Norman A. Turnquist

GE Corporate Research and Development

Niskayuna, NY

T.W. Tseng

GE Aircraft Engines

Cincinnati, $\mathrm{OH}$

\author{
A.D. McNickle \\ Stein Seal Co. \\ Kulpsville, PA \\ B.M. Steinetz \\ NASA John H. Glenn Research Center \\ at Lewis Field \\ Cleveland, $\mathrm{OH}$
}

1999 NASA Seal/Secondary Air System Workshop

October 28-29, 1999

NASA John H. Glenn Research Center at Lewis Field 


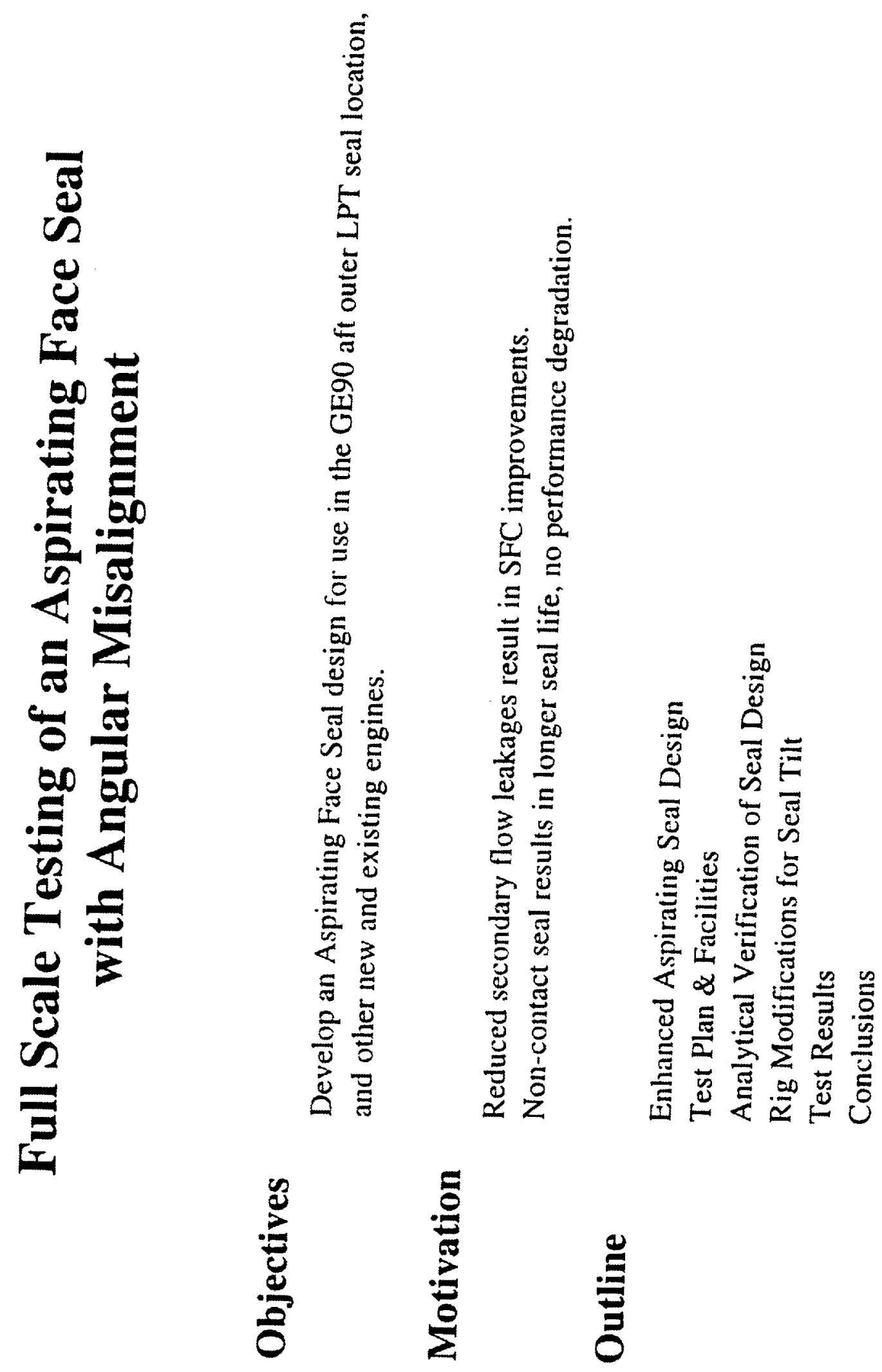




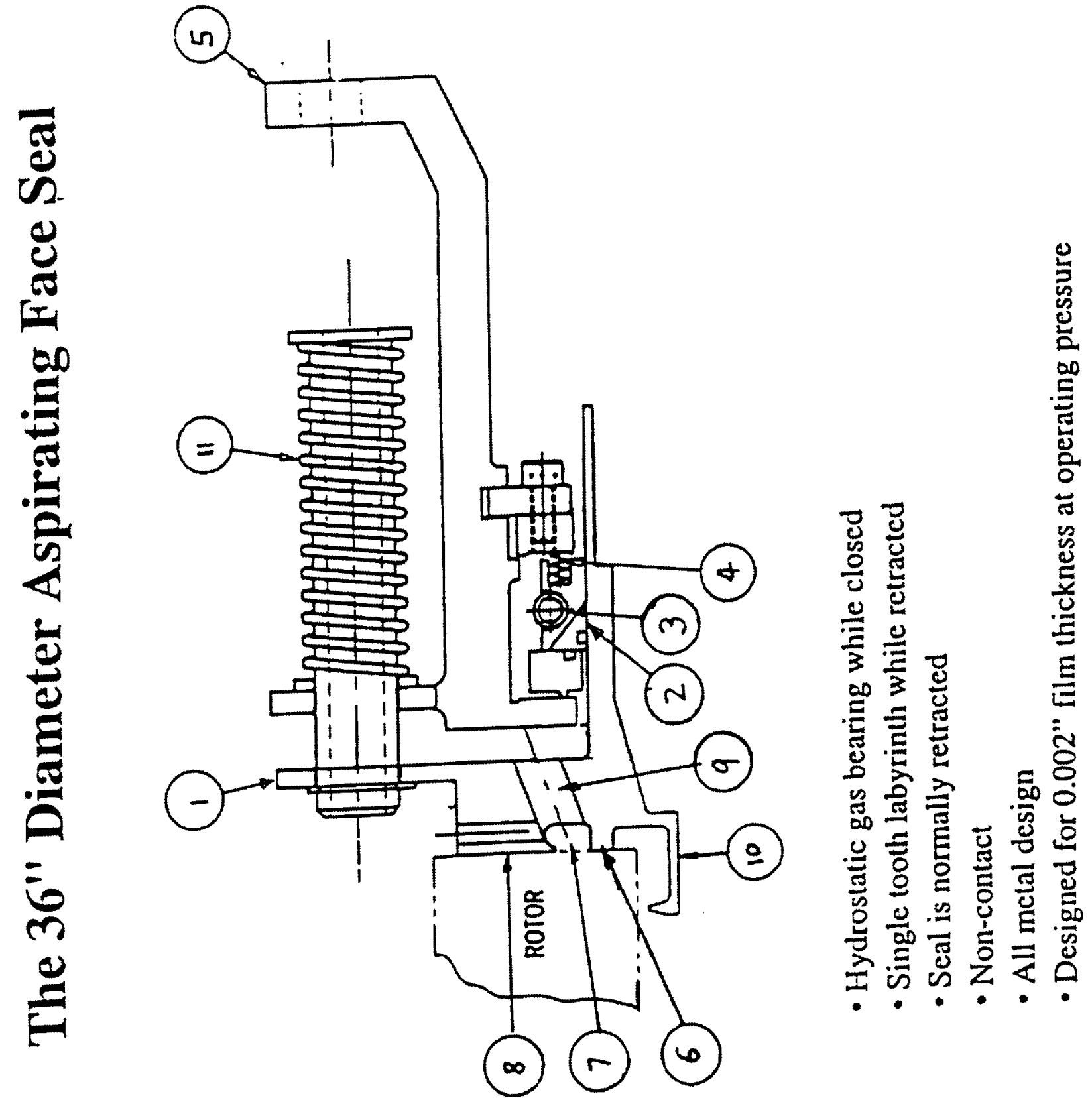




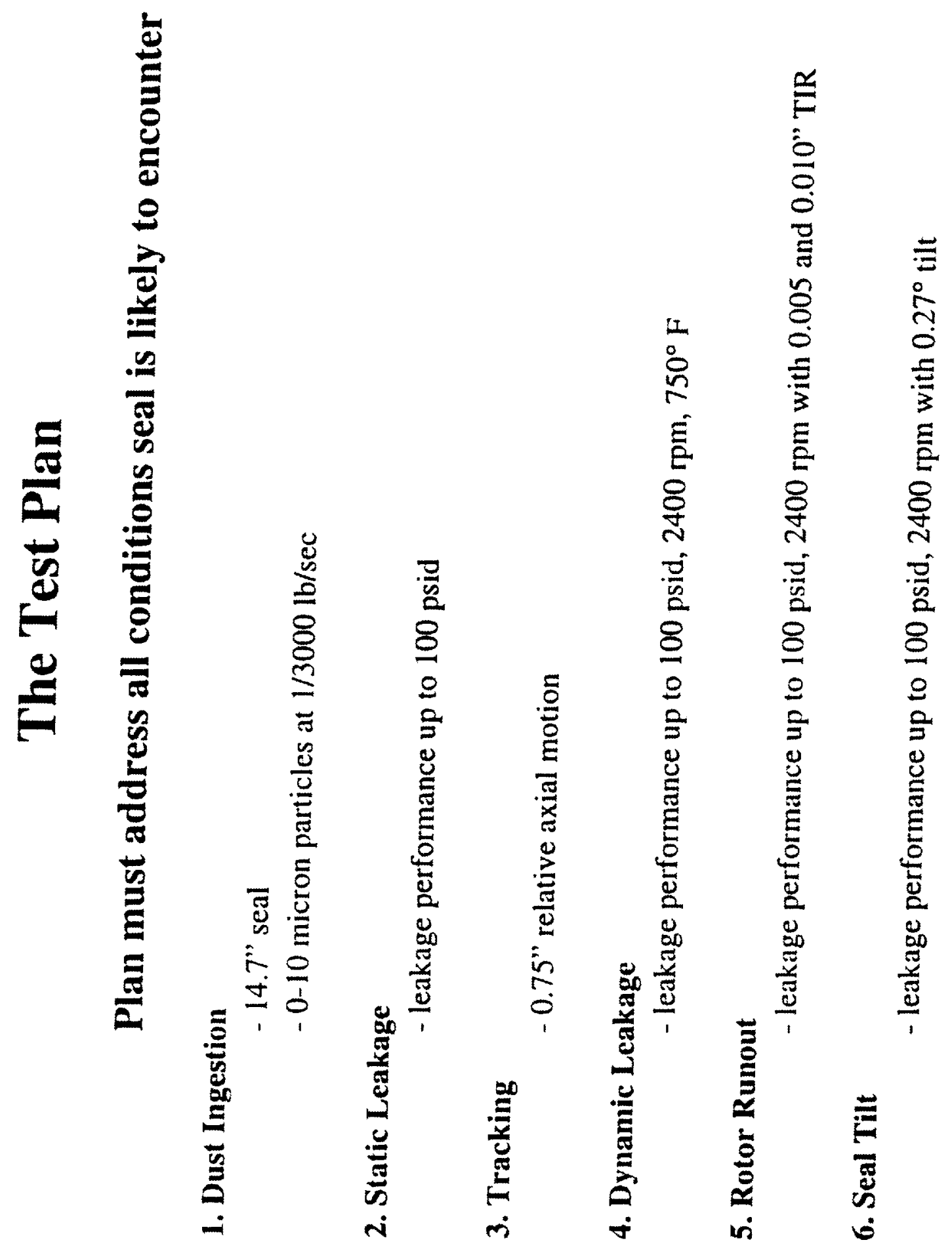



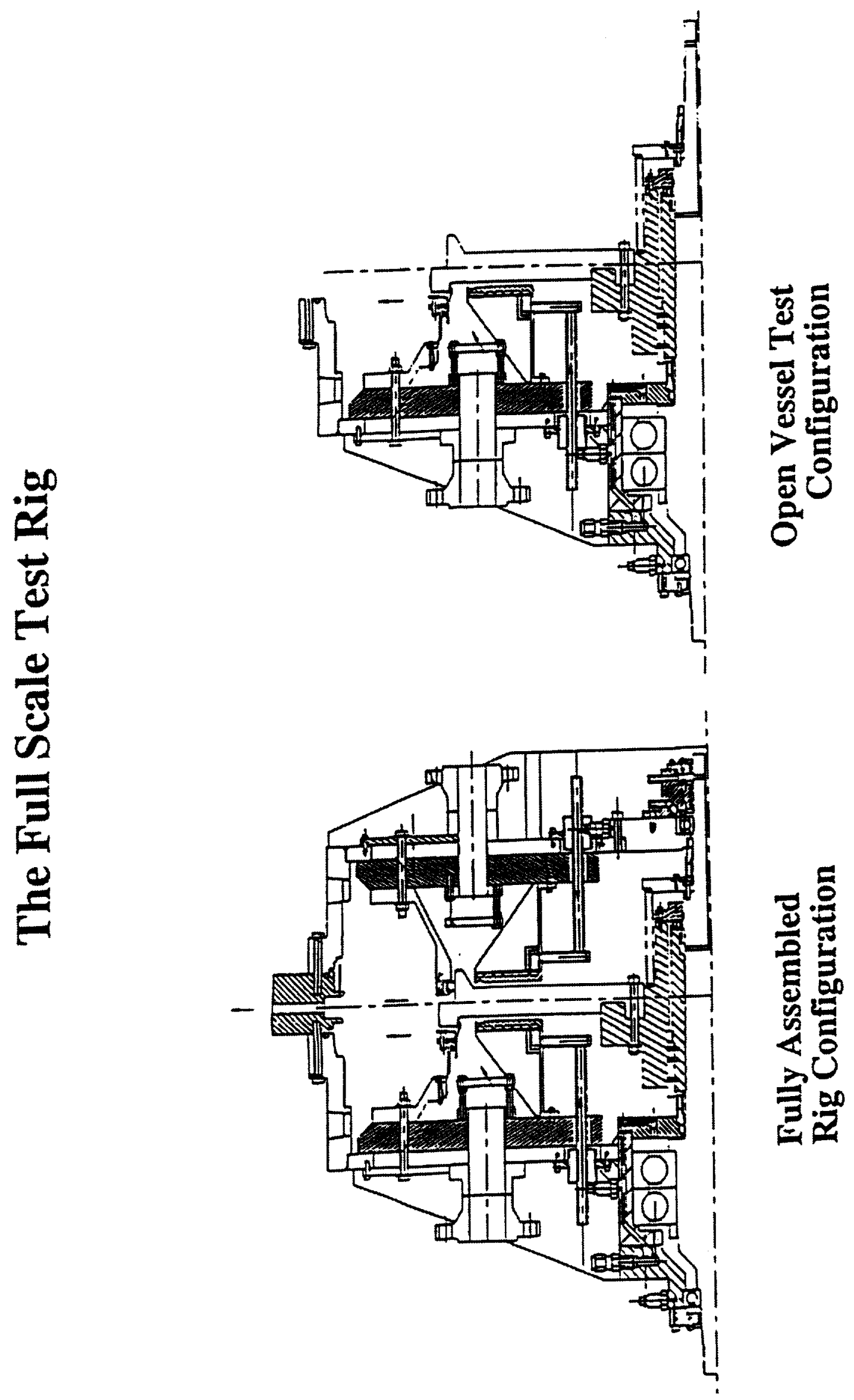


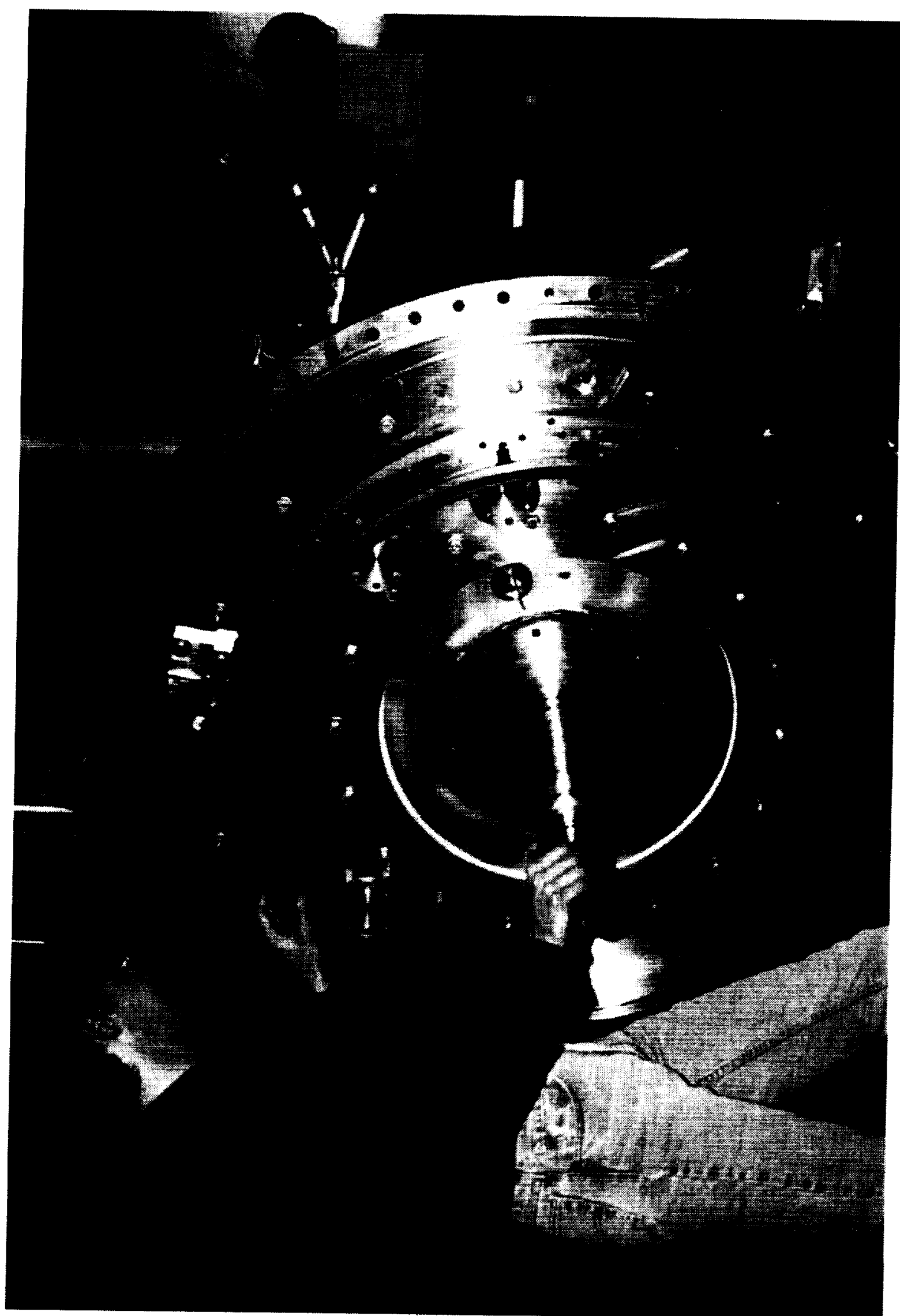

Photograph of the Open Full Scale Test Rig with the Aspirating Seal Installed 


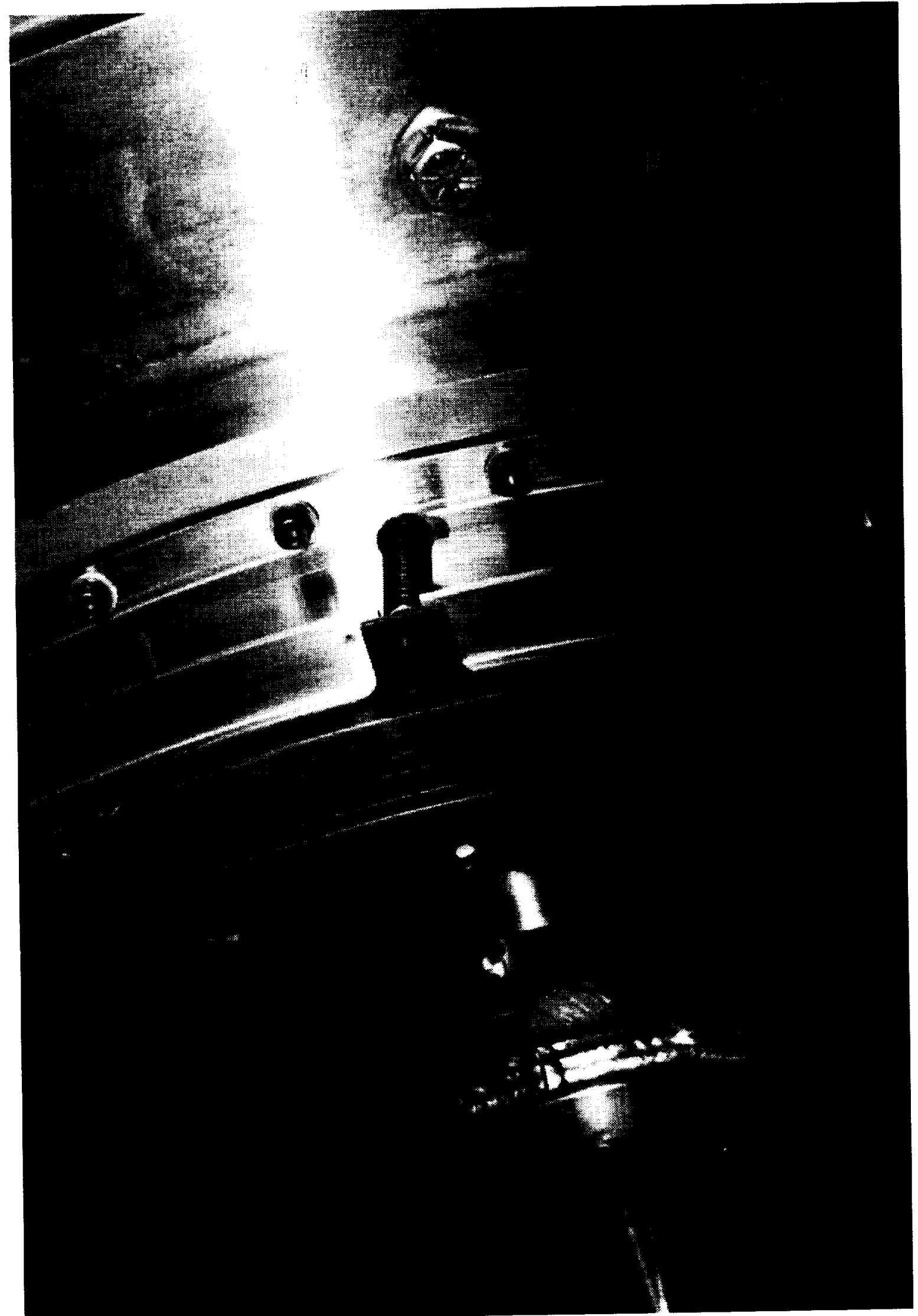

Detailed Photograph of the Aspirating Seal showing the Air Bearing Face and Orifice Holes 


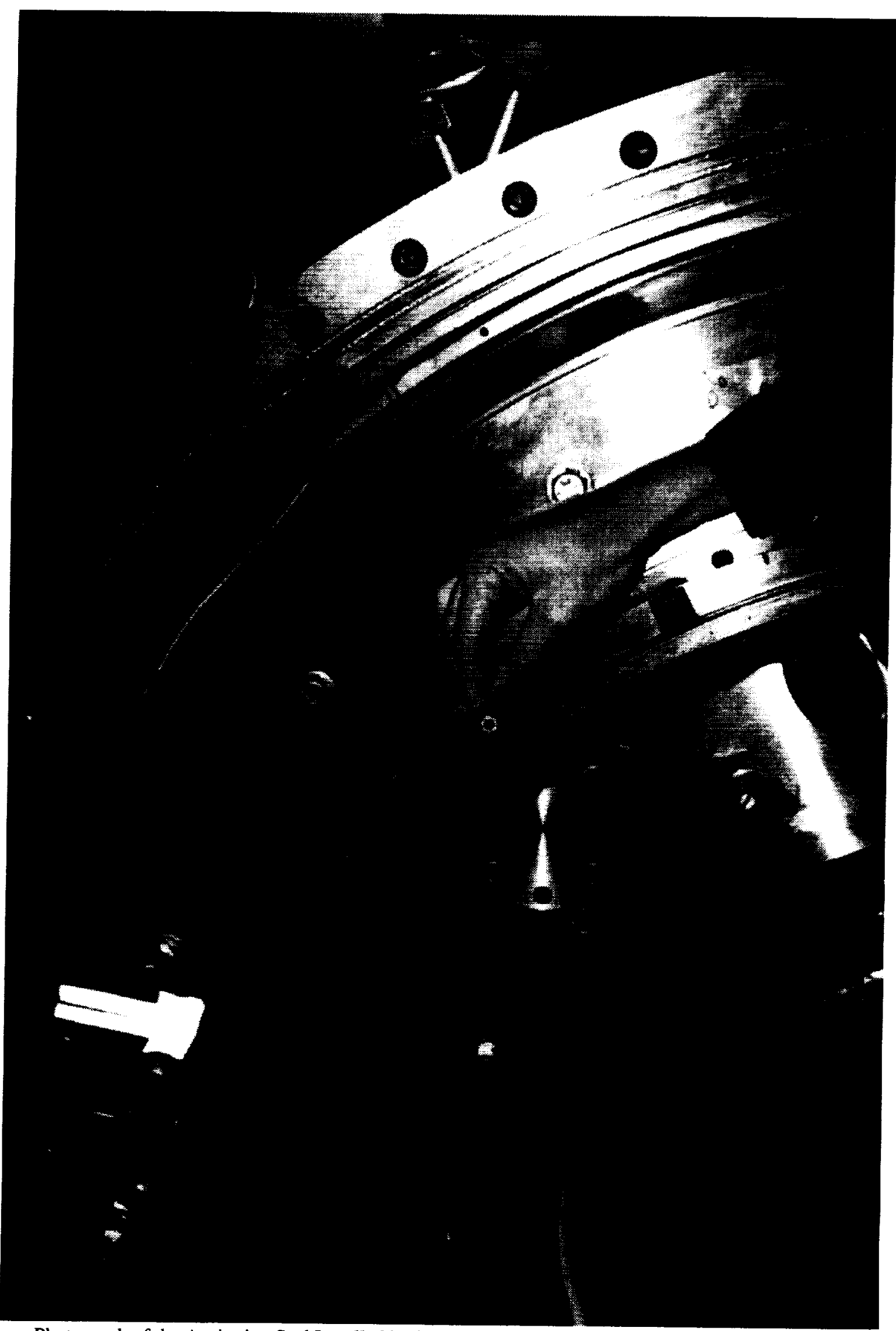

Photograph of the Aspirating Seal Installed in the Full Scale Test Rig showing Axial Contact Probe 




Photograph of the Full Scale Test Rig Rotor 


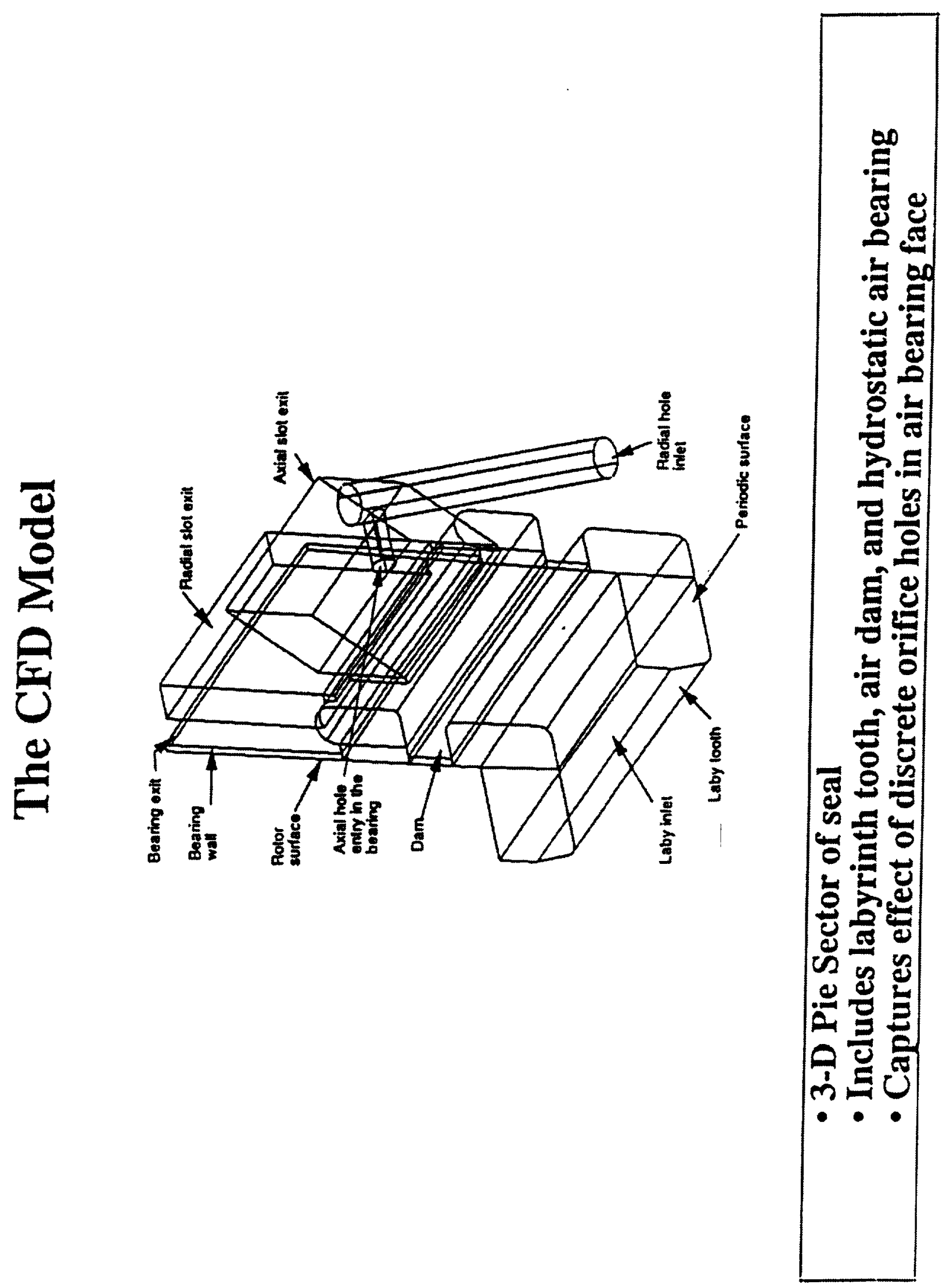




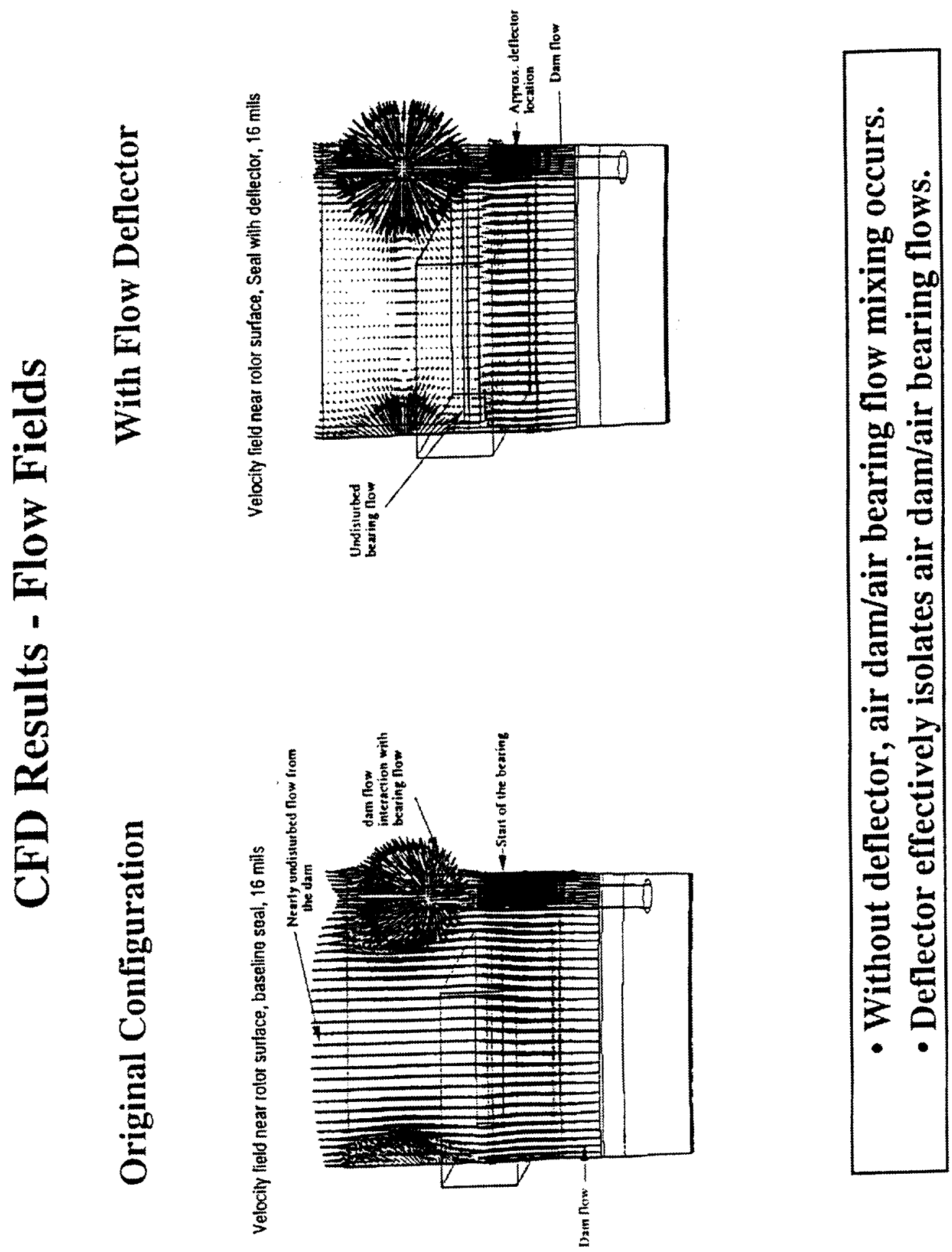




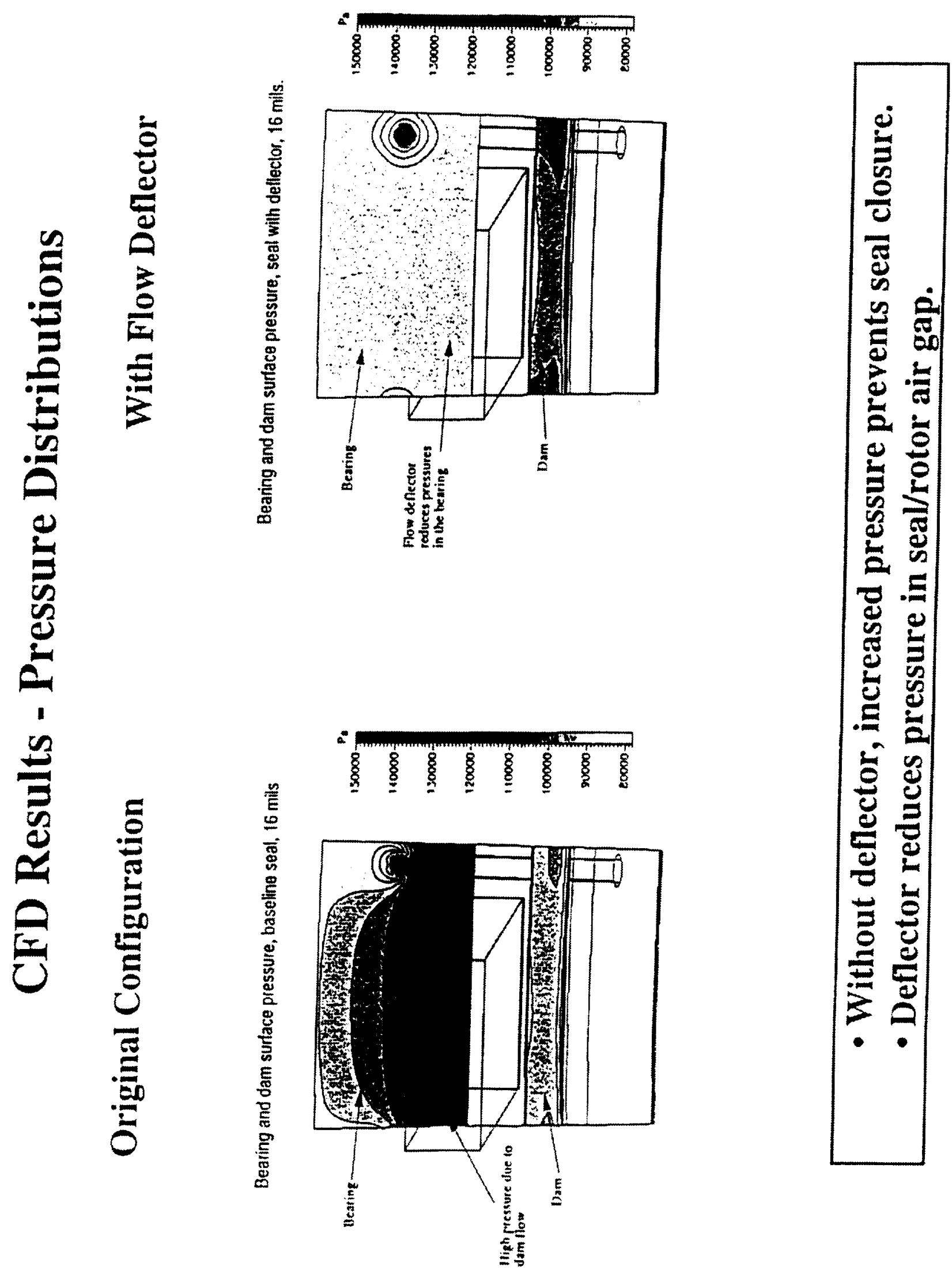




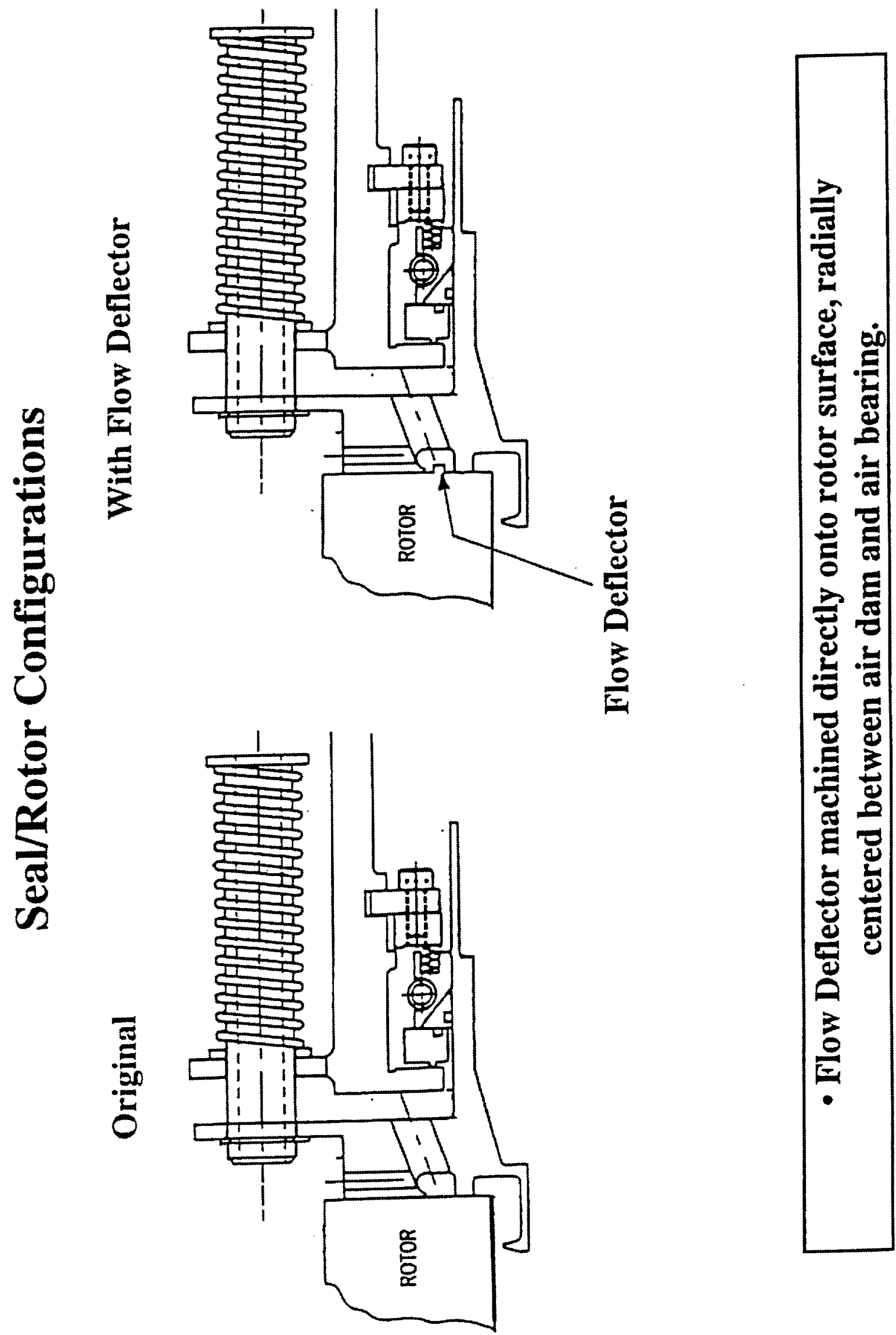




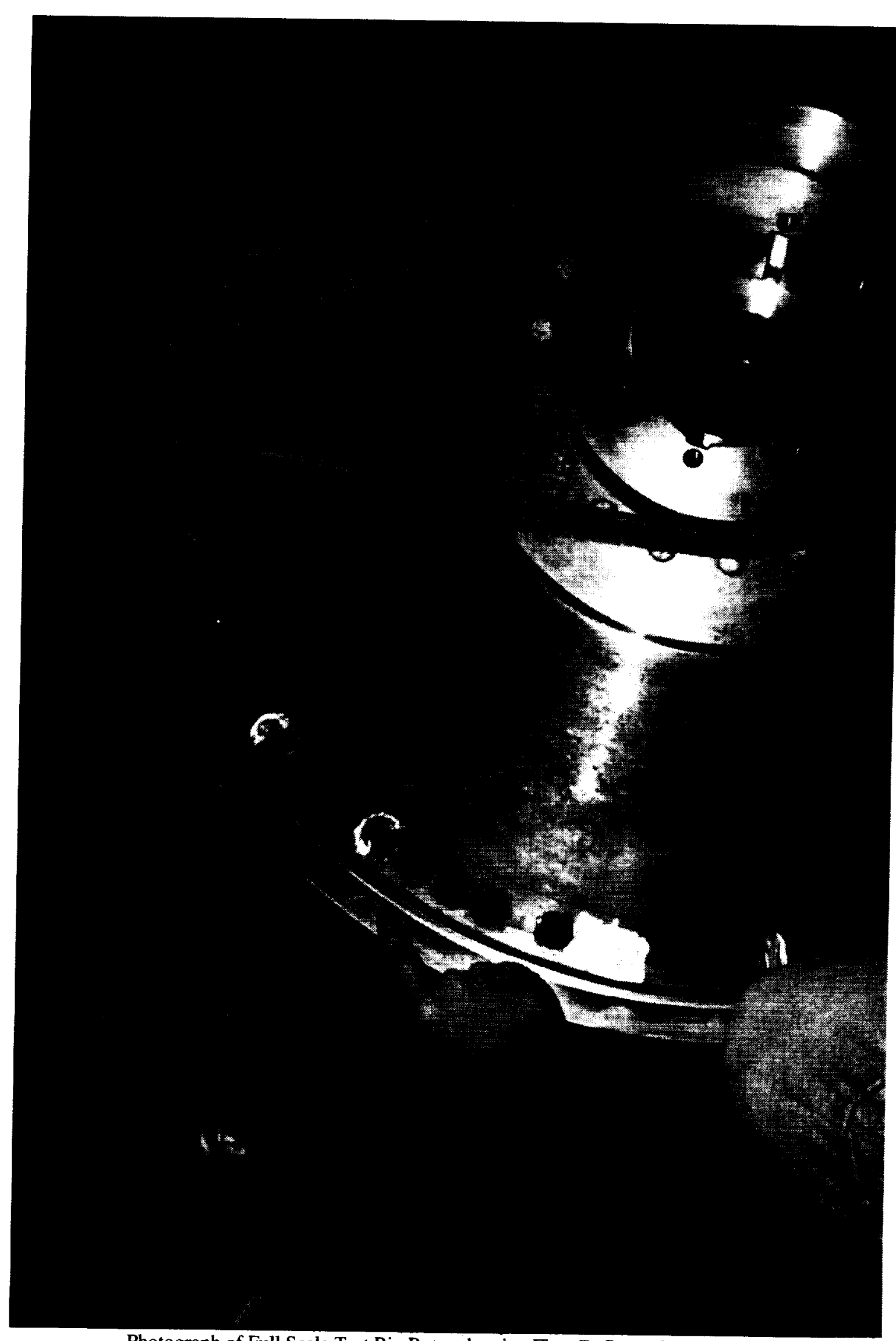

Photograph of Full Scale Test Rig Rotor showing Flow Deflector Modification 


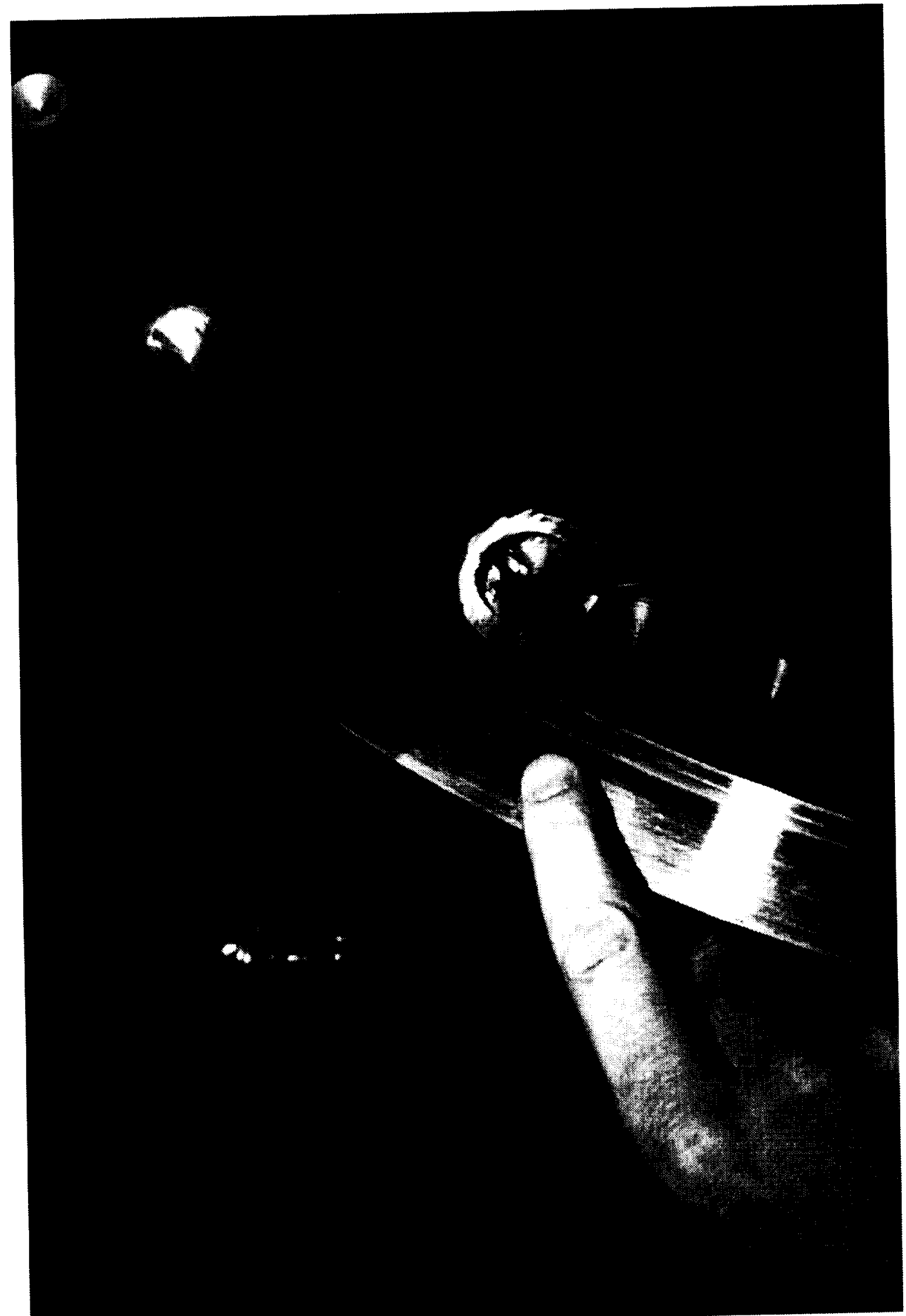

Detailed Photograph of Full Scale Test Rig Rotor showing Flow Deflector Modification 


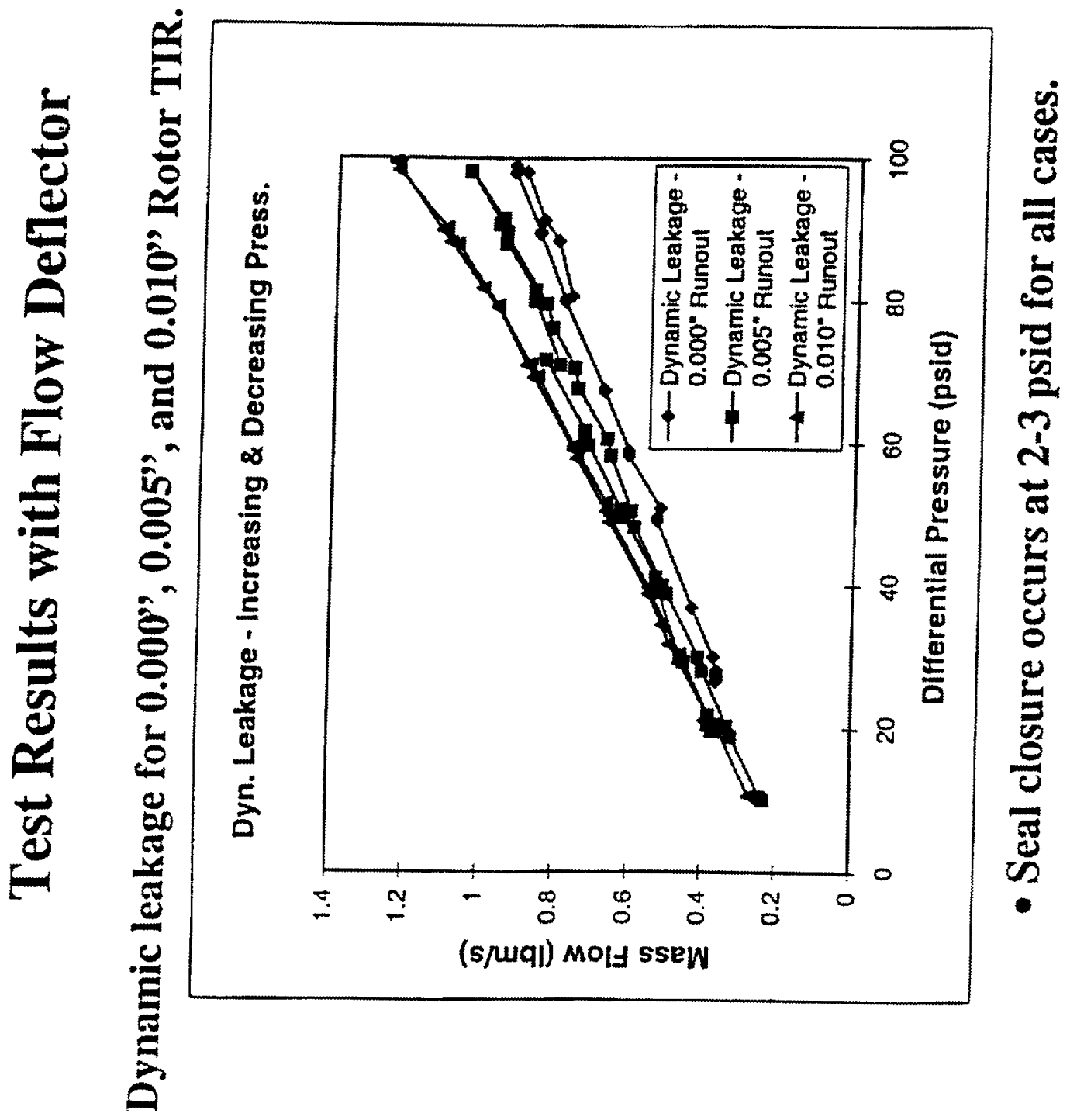




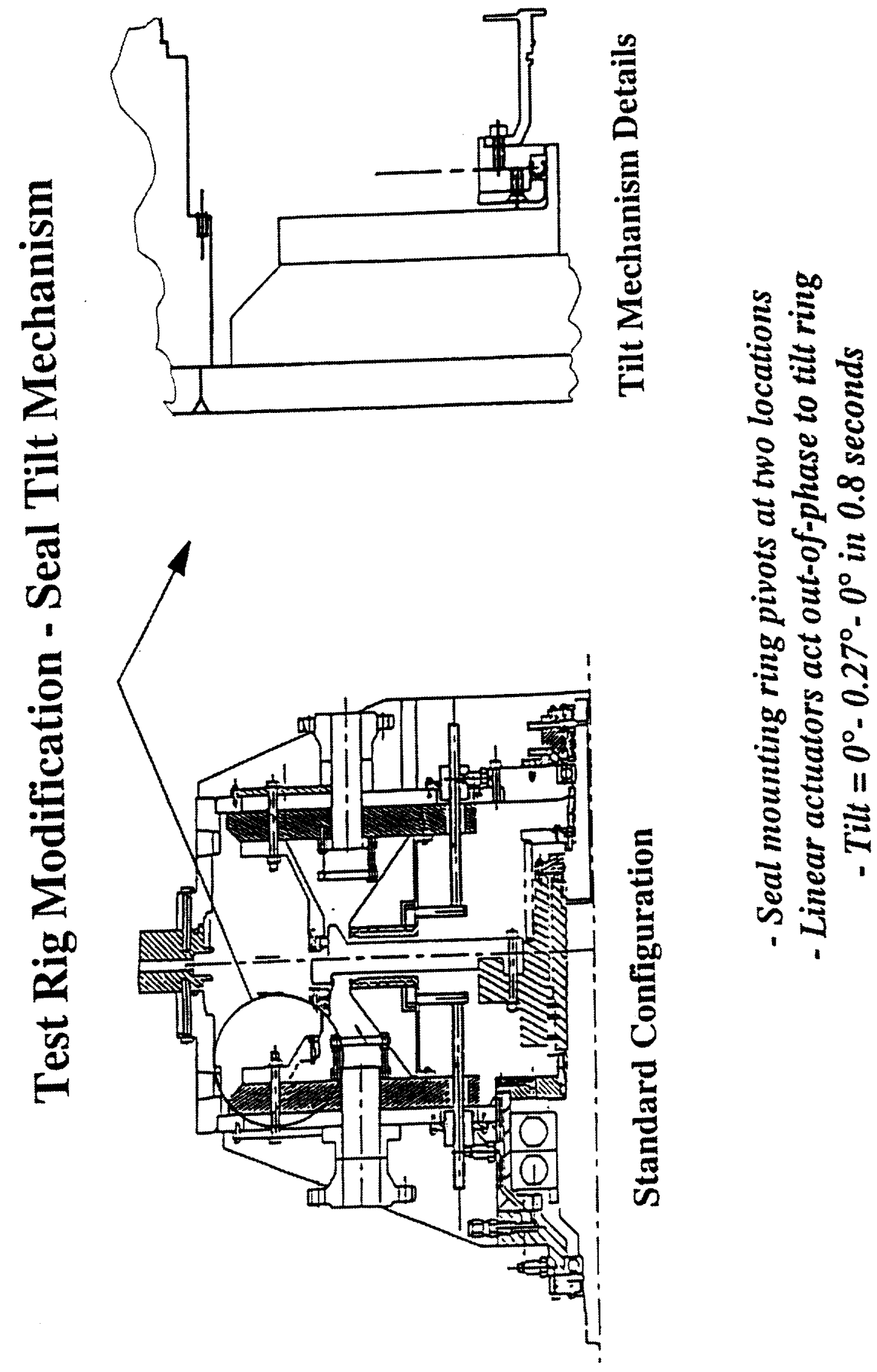




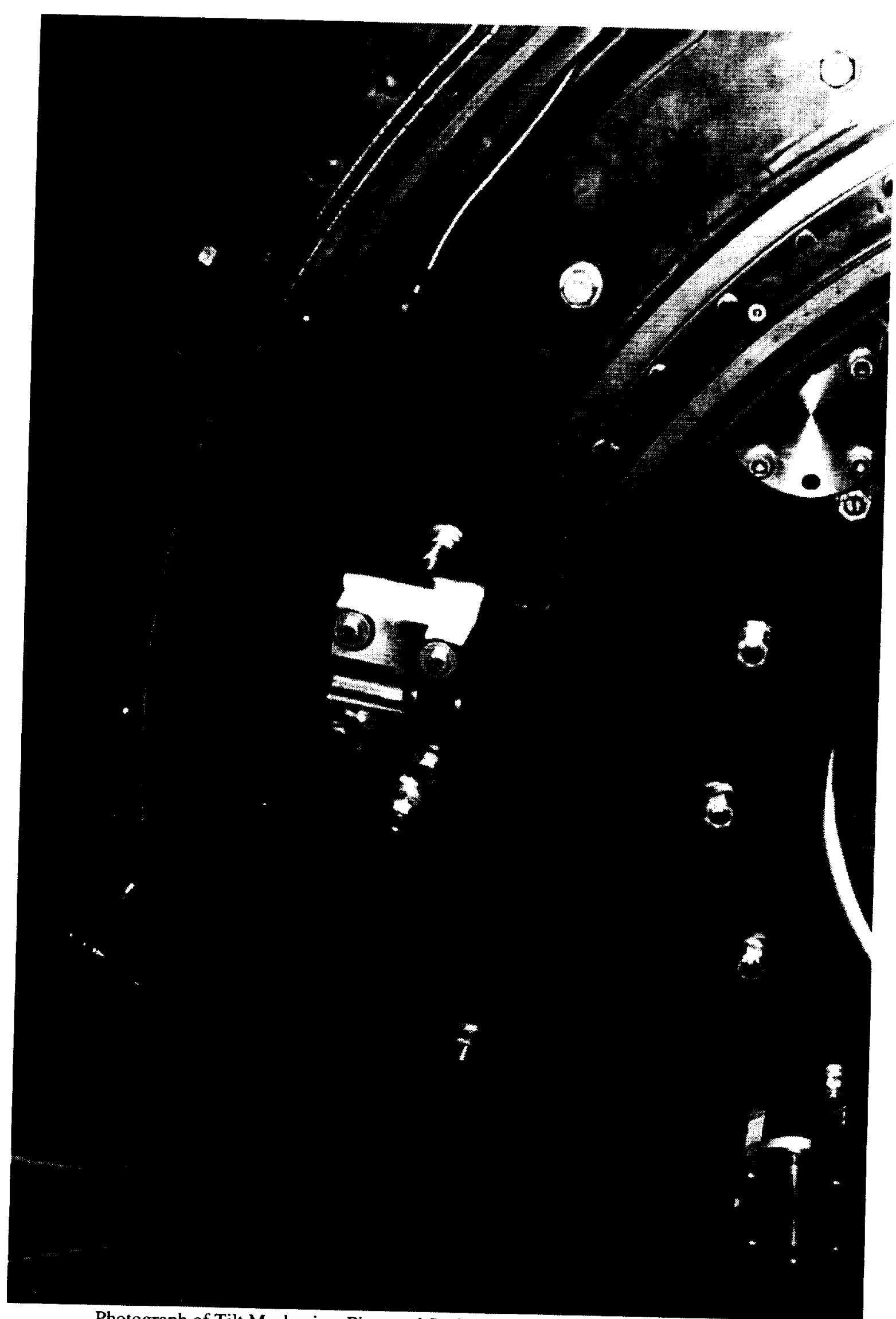

Photograph of Tilt Mechanism Pivot and Seal Holder with Aspirating Seal Installed 


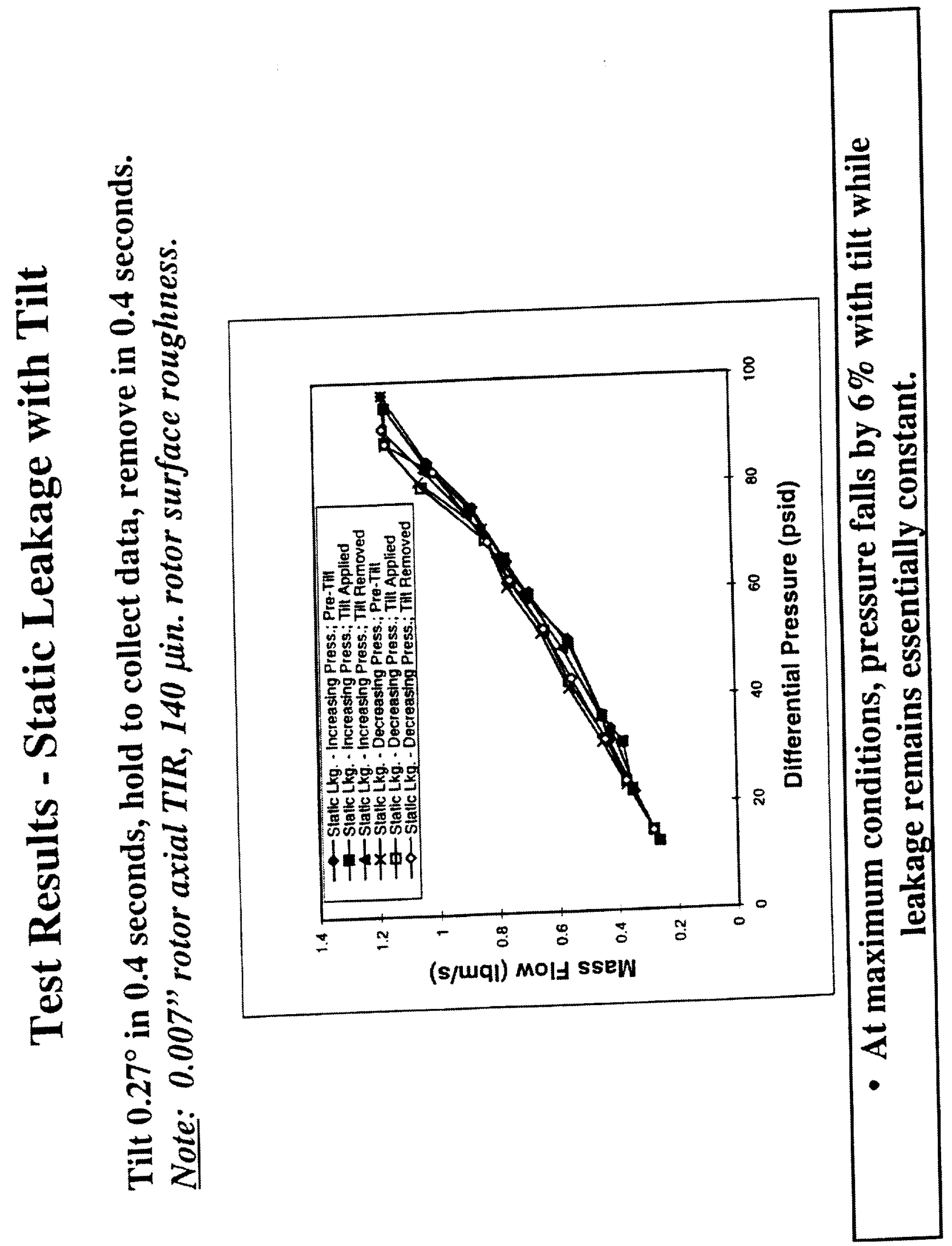




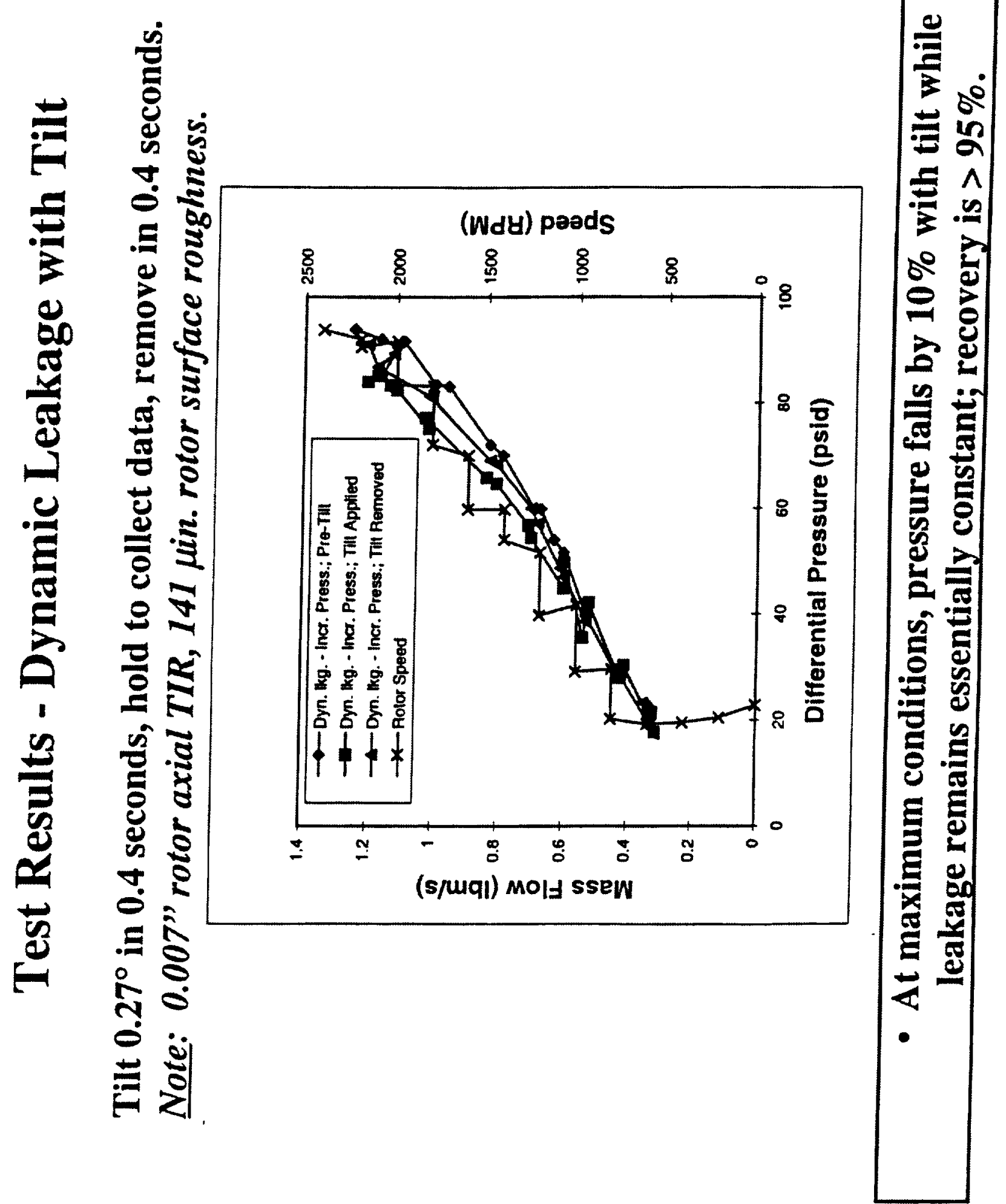




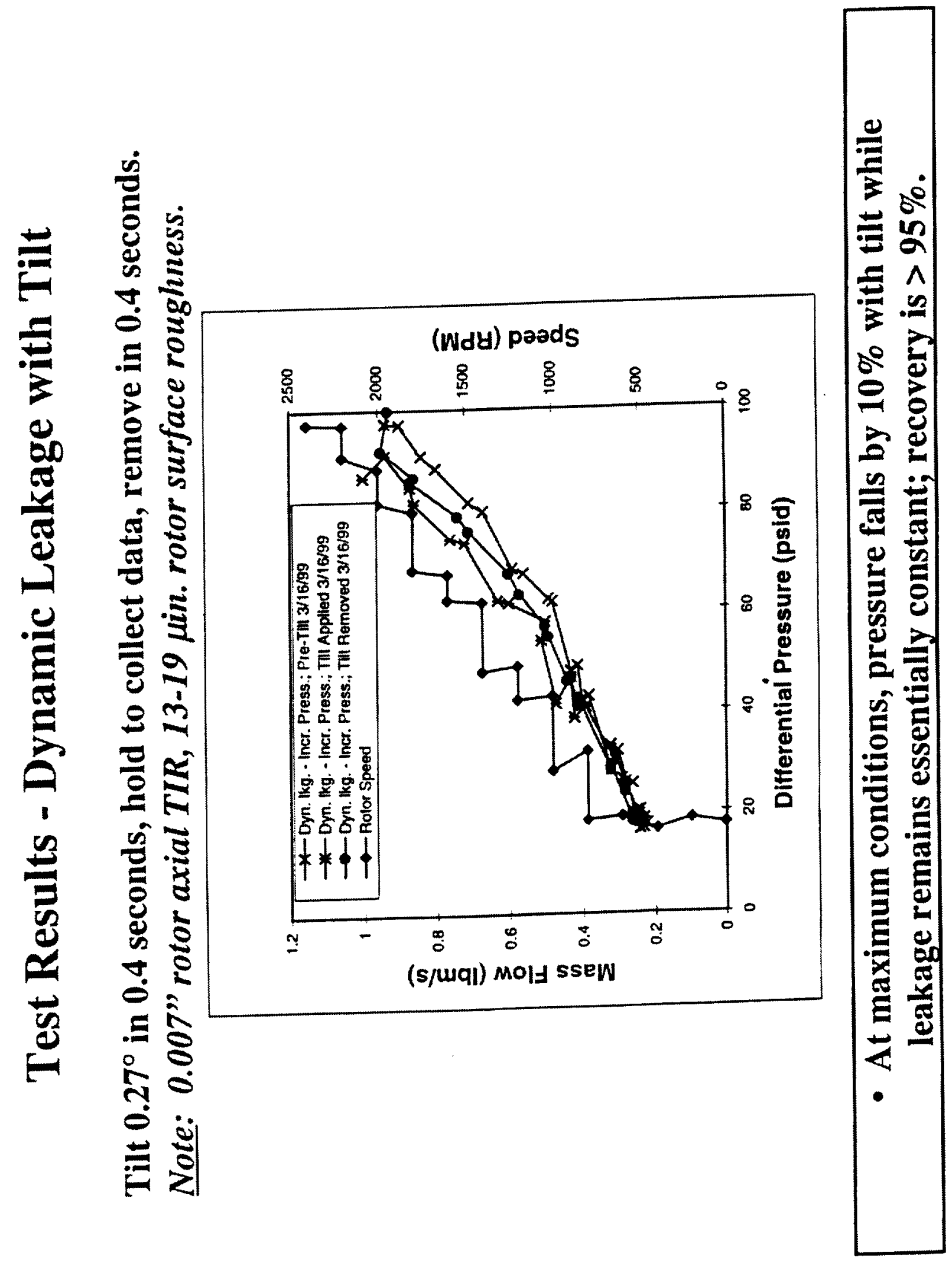




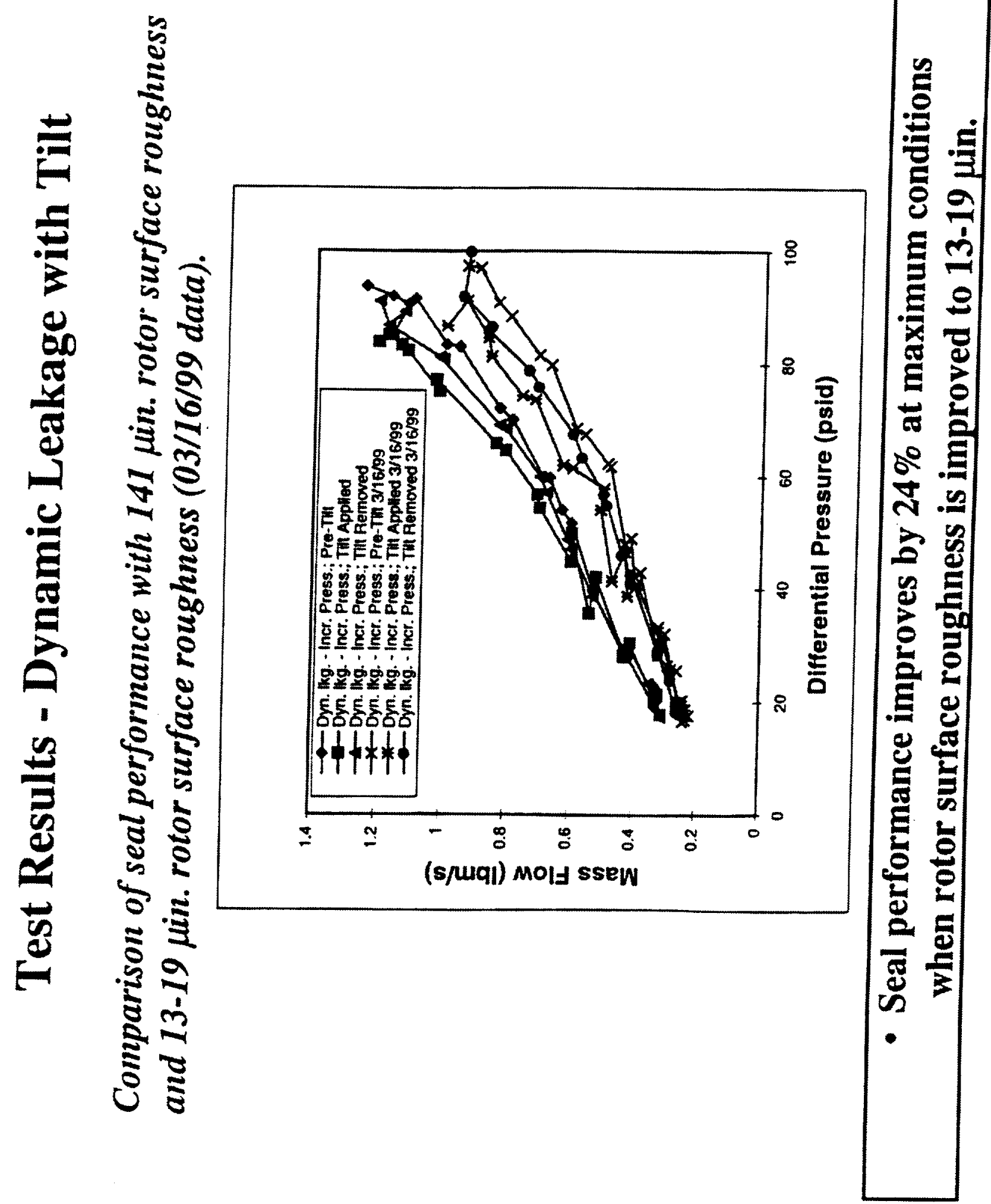




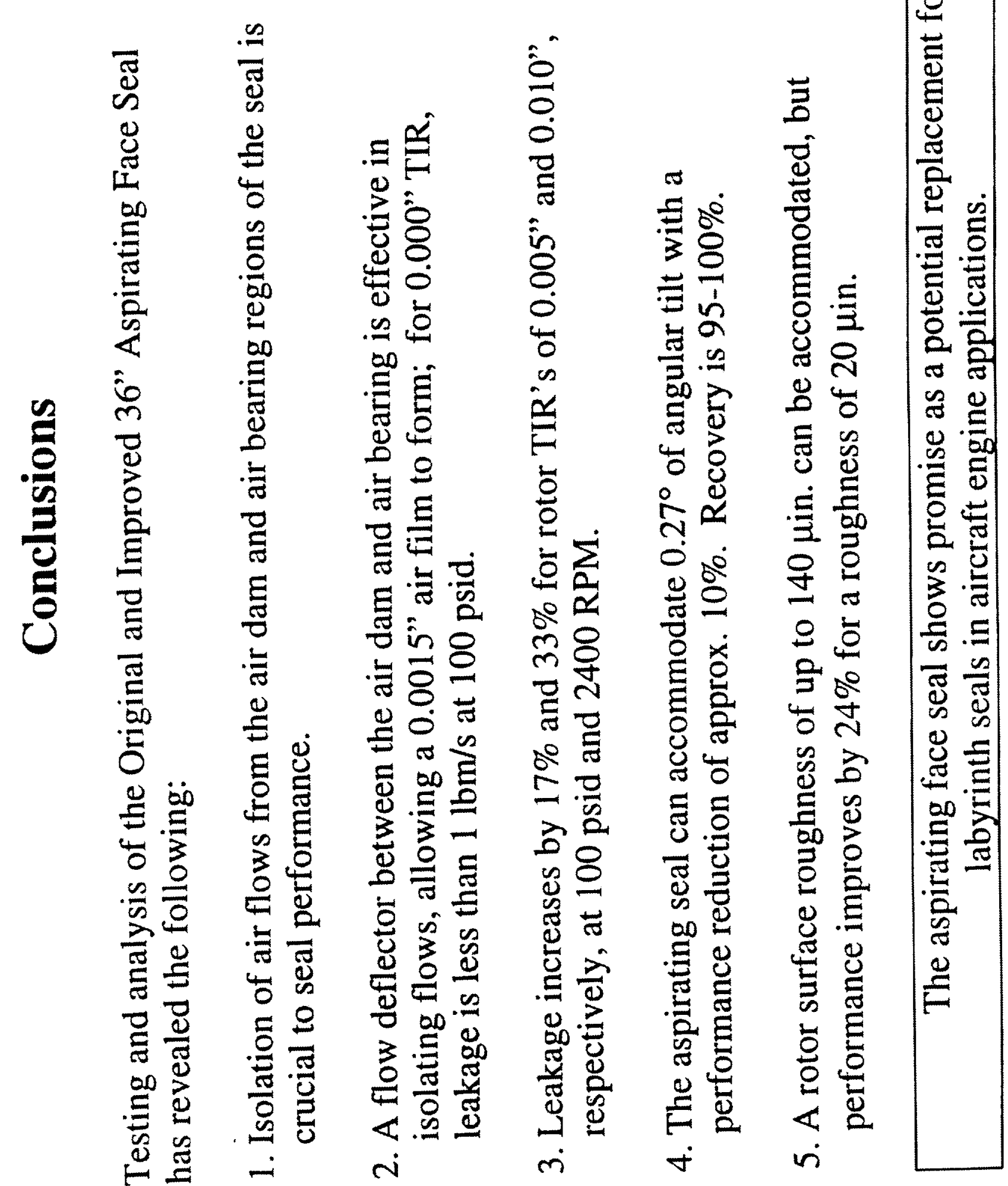




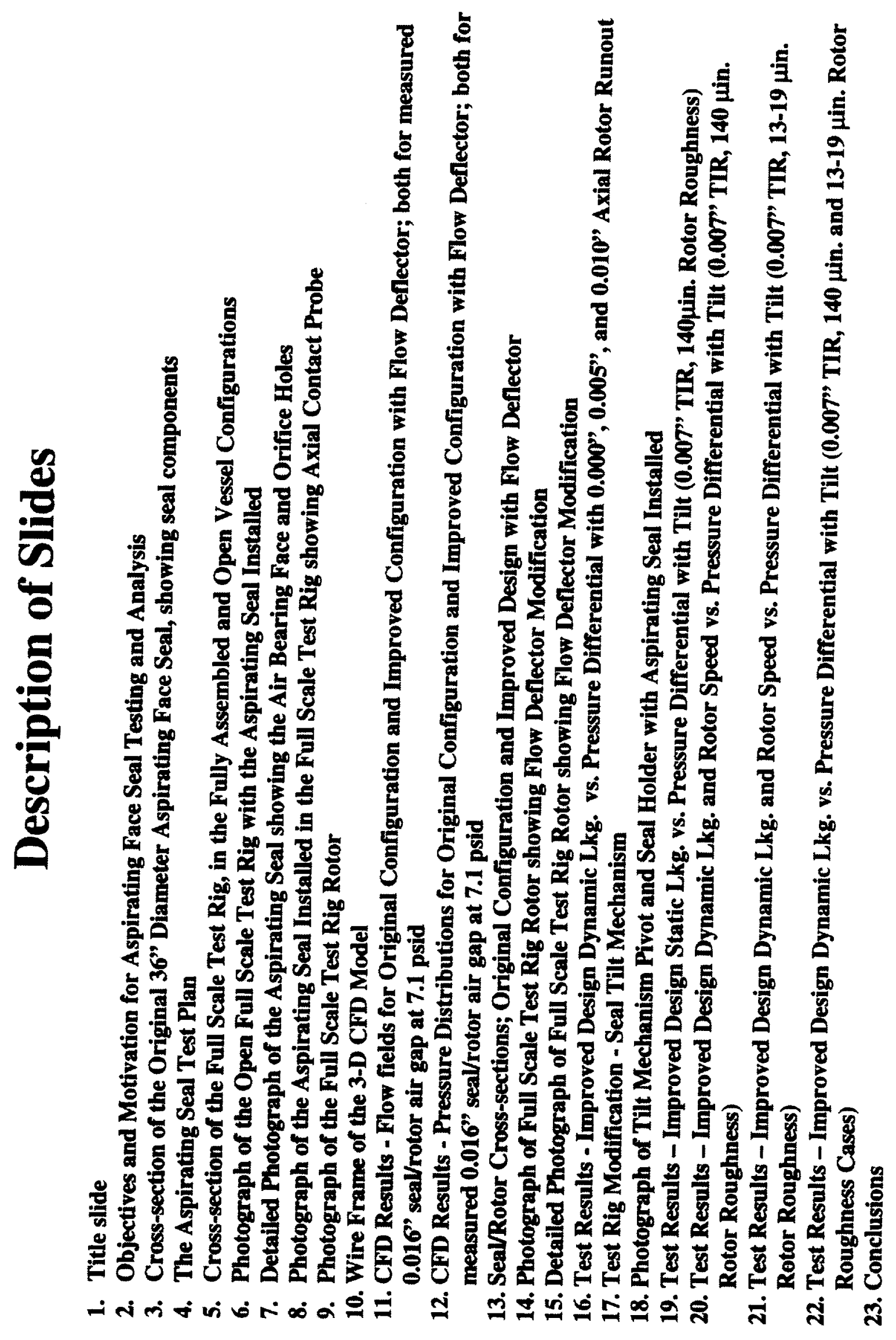

